Journal of Business Administration Vol 3, No 1, Maret 2019, hlm. 22-28. e-ISSN:2548-9909

\title{
ANALISIS PERILAKU KONSUMEN YANG MEMPENGARUHI PEMILIHAN TEMPAT WISATA PANTAI DENDANG MELAYU BATAM
}

\author{
Muhammad Rasyid Ridho Lubis ${ }^{1}$, Dwi Kartikasari² \\ 1) Jurusan Manajemen Bisnis, Politeknik Negeri Batam, Batam, Indonesia \\ email: rasyidridholubis04@gmail.com, \\ 2) Jurusan Manajemen Bisnis, Politeknik Negeri Batam, Batam, Indonesia \\ email: dwi@polibatam.ac.id
}

\begin{abstract}
Dendang Melayu Beach is a public beach that is being developed by the Batam City Government. Although various efforts have been made by the government to increase the number of visitors to this beach, it turns out that the number of visitors has not necessarily increased consistently but fluctuated up and down. Therefore, this research was carried out to further explore the behavior of visitors in the hope that it could become a material evaluation of the government in developing this tourist attraction. This study aims to examine the effect of consumer behavior on the selection of Dendang Melayu Beach tourist attractions. The respondents of this study were 100 tourists who visited the Batam Dendang Beach. The data analysis method used is inductive statistics using multiple linear regression. The results of this study are the four variables of consumer behavior namely cultural, social, personal and psychological factors partially positive and significant effect on the choice of tourist attractions.
\end{abstract}

Keywords: Consumer behavior, Batam, tourism, Malay

\begin{abstract}
Abstrak
Pantai Dendang Melayu adalah pantai umum yang sedang dikembangkan oleh Pemerintah Kota Batam. Meskipun berbagai upaya telah dilakukan oleh pemerintah untuk terus meningkatkan jumlah pengunjung pantai ini, ternyata jumlah pengunjungnya tidak serta-merta meningkat secara konsisten tetapi berfluktuasi naik turun. Oleh sebab itu, penelitian ini dilaksanakan untuk lebih mendalami perilaku pengunjung dengan harapan dapat menjadi bahan evaluasi pemerintah dalam mengembangkan objek wisata ini. Penelitian ini bertujuan untuk menguji pengaruh perilaku konsumen terhadap pemilihan tempat wisata Pantai Dendang Melayu. Responden penelitian ini adalah sejumlah 100 wisatawan yang berkunjung ke Pantai Dendang Melayu Batam. Metode analisis data yang digunakan adalah statistik induktif dengan menggunakan regresi linier berganda. Hasil dari penelitian ini adalah keempat variabel dari perilaku konsumen yaitu faktor budaya, sosial, pribadi dan psikologi secara parsial berpengaruh positif dan signifikan terhadap pemilihan tempat wisata.
\end{abstract}

Kata Kunci: Perilaku konsumen, Batam, wisata, Melayu 


\section{PENDAHULUAN}

Indonesia adalah negara yang terletak di garis khatulistiwa, beriklim tropis, dan merupakan negara dengan garis pantai terpanjang di dunia yang membuat Indonesia menjadi daerah tujuan wisata yang memadai untuk dikelola dengan baik. Selain memiliki keindahan alam yang eksotis, Indonesia juga mempunyai beragam suku dan budaya yang unik yang menjadi daya tarik tersendiri pariwisata di Indonesia. Hal ini tentu menguntungkan dalam bidang kepariwisataan. Indonesia juga memiliki berbagai macam destinasi wisata yang baik untuk dikunjungi salah satunya adalah Batam.

Pariwisata di kota Batam saat ini terus tumbuh dengan mengembangkan destinasi wisata yang baru guna melengkapi tujuan wisata yang sudah ada. Penambahan destinasi wisata ini sebanding dengan posisi Batam yang merupakan gerbang utama arus masuk wisatawan macanegara. Jumlah wisatawan mancanegara yang masuk ke Batam mengalami kenaikan, hal ini akan sangat bagus untuk pertumbuhan perekonomian Kota Batam. Hal ini juga membuat pemerintah Kota Batam bersemangat untuk terus mengembangkan destinasi destinasi wisata baru maupun destinasi wisata yang sudah ada.

Salah satu destinasi wisata yang sedang dikembangkan adalah Pantai Dendang Melayu yang terletak di kecamatan Sagulung, Kota Batam. Pantai Dendang Melayu memiliki daya tarik dan potensi dalam peningkatan pendapatan daerah dan menjadi salah satu aset wisata bahari di Batam yang dikembangkan.

Pantai Dendang Melayu dapat menjadi salah satu pariwisata favorit di Batam yang memiliki panorama yang indah dan dilengkapi dengan fasilitas penunjang seperti panggung hiburan, anjungan, gazebo, taman, dan fasilitas lainnya. Pantai ini juga sering mengadakan hiburan pada hari-hari tertentu. Hiburan tersebut dijadikan sebagai salah satu daya tarik wisatawan lokal maupun asing untuk berkunjung.
Menurut Dinas Pariwisata dan Kebudayaan Kota Batam, tahun 2017, wisatawan lokal maupun asing yang berkunjung ke Pantai Dendang Melayu setiap bulannya terus mengalami fluktuasi naik turun seperti dapat dilihat pada tabel di bawah ini.

Tabel 1. Jumlah Kunjungan Wisata Pantai Dendang

\begin{tabular}{|c|c|c|c|}
\multicolumn{5}{c}{ Melayu Tahun 2017} \\
\hline Bulan & Lokal & Mancanegara & Jumlah \\
\hline Januari & 12.549 & 3.411 & 15.960 \\
\hline Februari & 7.609 & 923 & 8.532 \\
\hline Maret & 4.976 & 1.164 & 6.140 \\
\hline April & 4.028 & 797 & 4.825 \\
\hline Mei & 3.673 & 860 & 4.533 \\
\hline Juni & 2.423 & 833 & 3.256 \\
\hline Juli & 3.297 & 518 & 3.815 \\
\hline Agustus & 1.924 & 323 & 2.247 \\
\hline September & 4.226 & 1.441 & 5.667 \\
\hline Oktober & 3.929 & 1.847 & 5.776 \\
\hline November & 3.518 & 2.160 & 5.678 \\
\hline Desember & 5.047 & 2.525 & 7.572 \\
\hline Jumlah & $\mathbf{5 7 . 1 9 9}$ & $\mathbf{1 6 . 8 0 2}$ & $\mathbf{7 4 . 0 0 1}$ \\
\hline
\end{tabular}

Dari tabel di atas dapat dilihat bahwa perkembangan jumlah wisatawan pada tempat wisata Pantai Dendang Melayu Batam dari bulan ke bulan mengalami perubahan, berupa peningkatan dan penurunan. Salah satu faktor yang mempengaruhi kedatangan wisatawan adalah perilaku konsumen dalam memilih tempat wisata. Perilaku konsumen dalam memilih tempat wisata ini dipengaruhi oleh beberapa faktor yaitu faktor budaya, faktor sosial, faktor pribadi dan faktor psikologi.

\section{LANDASAN TEORI Perilaku konsumen}

perilaku konsumen menyangkut suatu proses pengambilan keputusan sebelum pembelian sampai dengan mengkonsumsi produk dan tujuan mempelajari perilaku konsumen adalah untuk menyusun strategi pemasaran yang berhasil (Supriyono dan Iskandar, 2015).

Perilaku konsumen menjelaskan tentang bagaimana individu, kelompok, dan organisasi memilih, membeli, menggunakan, dan bagaimana barang, jasa, jasa, ide, atau pengalaman untuk memuaskan kebutuhan dan keinginan mereka (Kotler dan Keller, 2008). Faktor- 
faktor yang mempengaruhi perilaku konsumen adalah kebudayaan, faktor sosial, pribadi, dan faktor psikologi.

\section{Faktor Budaya}

Faktor budaya merupakan kumpulan nilai-nilai dasar dan sekelompok orang yang mempunyai sistem nilai sama berdasarkan pada pengalaman hidup dan situasi (Yuriska dan Sukirno, 2014). Kebudayaan sangat mempengaruhi perilaku pembelian konsumen. Kebudayaan adalah penyebab paling dasar dan perilaku seseorang. Perilaku manusia sebagian besar dipelajari. Dibesarkan di masyarakat, anak belajar nilai-nilai dasar, persepsi, keinginan, dan perilaku dari keluarganya dan lembaga penting lainnya (Malau, 2017).

\section{Faktor Sosial}

Faktor sosial yaitu dua orang atau kelompok atau lebih yang berinteraksi untuk mencapai sasaran individu atau bersama hampir setiap masyarakat memiliki beberapa sturuktur kelas sosial (Yuriska dan Sukirno, 2014). Kelas sosial tidak ditentukan oleh faktor tunggal seperti pendapatan, tetapi diukur sebagai kombinasi dari pekerjaan, pendapatan, pendidikan, kekayaan, dan variabel lainnya (Malau, 2017).

\section{Faktor Pribadi}

Faktor pribadi adalah sesuatu atau aspek yang melekat pada diri seorang individu yang mempengaruhi perilakunya (Yuriska dan Sukirno, 2014). Kepribadian merupakan suatu karakteristik individu mengenai kecenderungan merespon lintas situasi yang mirip (Supranto dan Limakrisna, 2011).

\section{Faktor Psikologi}

Faktor psikologi adalah segala sesuatu aspek yang mampu mencitrakan/menggerakkan diri seorang individu berdasarkan ukuran motivasi, persepsi, pembelajaran maupun sikap pada setiap perilaku mereka (Yuriska dan Sukirno, 2014). Titik awal untuk memahami perilaku konsumen adalah respon rangsangan. Rangsangan pemasaran dan lingkungan memasuki kesadaran konsumen, dan sekelompok proses psikologis digabungkan dengan karakteristik konsumen tertentu menghasilkan proses pengambilan keputusan dan keputusan akhir pembelian.

\section{Kerangka Pemikiran}

Berdasarkan teori yang telah diuraikan dapat dibentuk kerangka pemikiran sebagai dasar hipotesis bahwa perliku konsumen diduga mempengaruhi keputusan pemilihan tempat wisata Pantai Dendang Melayu Batam seperti tampak pada gambar berikut:

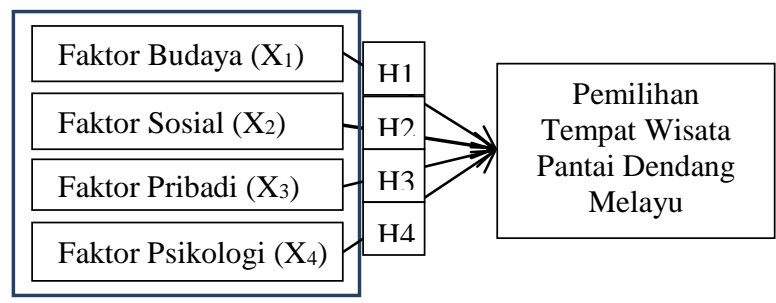

Gambar 1 Kerangka Pemikiran

\section{Pengaruh Faktor Budaya}

Kebudayaan sangat mempengaruhi perilaku pembelian konsumen. Rasa ingin tahu yang ada di dalam diri seseorang yang tinggi terkait kebudayaan masyarakat sekitar tempat wisata akan mempengaruhi perilaku dalam pemilihan tempat wisata.

\section{H1 : Faktor budaya berpengaruh positif dan signifikan terhadap pemilihan tempat wisata Pantai Dendang Melayu Batam}

\section{Pengaruh Faktor Sosial}

Faktor sosial mempengaruhi pemilihan tempat wisata, dikarenakan adanya dorongan dari lingkungan sekitar yang mempengaruhi keinginan seseorang dalam menentukan pilihan.

\section{H2 : Faktor sosial berpengaruh positif dan signifikan terhadap pemilihan tempat wisata Pantai Dendang Melayu Batam}

\section{Pengaruh Faktor Pribadi}

Dorongan terbesar dalam pemilihan tempat wisata tentunya didasari oleh 
keinginan diri sendiri yaitu terkait kebutuhan diri akan kesenangan di tempat wisata, keinginan untuk melakukan hal-hal baru di tempat wisata dan untuk memenuhi hasratnya.

\section{H3 : Faktor pribadi berpengaruh positif dan signifikan terhadap pemilihan tempat wisata Pantai Dendang Melayu Batam}

\section{Pengaruh Faktor Psikologi}

Dorongan dari dalam diri seseorang mempengaruhi pemilihan sesuatu berdasarkan atas keluwesan terhadap produk yang digunakan, keinginan yang lebih besar dan kemudahan penggunaan produk tersebut dibandingkan dengan yang lain.

\section{H4 : Faktor psikologi berpengaruh positif dan signifikan terhadap pemilihan tempat wisata Pantai Dendang Melayu Batam}

\section{Metodologi Penelitian}

Metode penelitian yang digunakan dalam penelitian ini adalah pendekatan kuantitatif. Variabel bebas yang terdapat pada penelitian ini adalah faktor budaya, faktor sosial, faktor pribadi, dan faktor psikologi. Variabel terikat yang ada pada penelitian ini berupa keputusan pemilihan. Penelitian ini menggunakan jenis primer. Dalam menentukan pengambilan sampel, digunakan non probability sampling (tidak acak) khususnya menggunakan purposive sampling. Menurut Sugiyono (2007) purposive sampling adalah teknik penentuan sampel dengan pertimbangan tertentu. Pertimbangan tersebut adalah kriteria yang digunakan dalam pengambilan sampel penelitian ini. Kriteria yang digunakan adalah sebagai berikut :

a. Masyarakat Kota Batam yang dilihat cukup dewasa untuk mengisi kuisioner (17 tahun keatas)

b. Frekuensi berkunjung ke Pantai Dendang Melayu Batam minimal 2 kali

Penetapan jumlah sampel dilakukan dengan menggunakan rumus Slovin dengan hasil jumlah responden sebanyak 100 orang.

\section{Validitas dan Reliabilitias}

Agar data yang diperoleh mempunyai tingkat akurasi dan konsistensi tinggi, maka instrumen penelitian yang akan digunakan harus valid dan reliabel. Karena signifikansi hasil koefisien korelasi seluruh item lebih besar dari 0,165 sehingga dapat disimpulkan bahwa seluruh item yang diuji dalam penelitian ini adalah valid (lihat tabel 2).

Suatu kuesioner dikatakan reliabel atau handal jika jawaban seseorang terhadap pernyataan adalah konsisten dari waktu ke waktu. Karena koefisien Cronbach's Alpha untuk variabel faktor budaya, faktor sosial, faktor pribadi, dan faktor psikologi lebih besar dari 0,60, dengan demikian dapat disimpulkan bahwa kuesioner yang digunakan oleh masing-masing variabel penelitian terbukti handal atau reliabel (lihat tabel 3).

Tabel 2. Hasil Uji Validitas

\begin{tabular}{|c|c|c|}
\hline \multicolumn{2}{|r|}{ 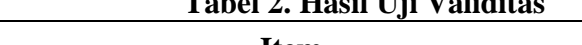 } & \multirow{3}{*}{$\begin{array}{c}\text { r hitung } \\
0,704\end{array}$} \\
\hline & Item & \\
\hline X1.1 & $\begin{array}{l}\text { Saya sudah biasa berwisata atau } \\
\text { melakukan kunjungan ke Pantai } \\
\text { Dendang Melayu }\end{array}$ & \\
\hline X1.2 & $\begin{array}{l}\text { Saya berwisata ke Pantai Dendang } \\
\text { Melayu karena tempatnya bagus dan } \\
\text { membuat betah }\end{array}$ & 0,562 \\
\hline X1.3 & $\begin{array}{l}\text { Saya berwisata ke Pantai Dendang } \\
\text { Melayu karena mudah dijangkau }\end{array}$ & 0,703 \\
\hline X1.4 & $\begin{array}{l}\text { Saya berwisata ke Pantai Dendang } \\
\text { Melayu Batam karena dekat dengan } \\
\text { tempat lahir saya }\end{array}$ & 0,643 \\
\hline X1.5 & $\begin{array}{l}\text { Saya berwisata ke Pantai Dendang } \\
\text { Melayu karena diminati banyak } \\
\text { orang }\end{array}$ & 0,671 \\
\hline X1.6 & $\begin{array}{l}\text { Saya berada di lingkungan yang } \\
\text { memiliki tingkat berwisata yang } \\
\text { tinggi }\end{array}$ & 0,660 \\
\hline $\mathrm{X} 2.1$ & $\begin{array}{l}\text { Saya berwisata ke Pantai Dendang } \\
\text { Melayu karena rekomendasi dari } \\
\text { teman }\end{array}$ & 0,590 \\
\hline $\mathrm{X} 2.2$ & $\begin{array}{l}\text { Saya berwisata ke Pantai Dendang } \\
\text { Melayu karena pengaruh dari teman }\end{array}$ & 0,592 \\
\hline $\mathrm{X} 2.3$ & $\begin{array}{l}\text { Saya berwisata ke Pantai Dendang } \\
\text { Melayu karena keputusan dari } \\
\text { keluarga }\end{array}$ & 0,571 \\
\hline $\mathrm{X} 2.4$ & $\begin{array}{l}\text { Saya berwisata ke Pantai Dendang } \\
\text { Melayu karena keluarga saya selalu } \\
\text { berwisata ke sana }\end{array}$ & 0,782 \\
\hline $\mathrm{X} 2.5$ & \begin{tabular}{lrrr} 
Peran & \multicolumn{2}{c}{ dalam } & \multicolumn{2}{r}{ masyarakat } \\
mempengaruhi & saya & dalam \\
berwisata & ke & Pantai & Dendang \\
\end{tabular} & 0,626 \\
\hline X2.6 & $\begin{array}{l}\text { Saya memilih berwisata ke Pantai } \\
\text { Dendang Melayu karena sudah } \\
\text { sesuai dengan status saya saat ini }\end{array}$ & 0,330 \\
\hline
\end{tabular}


Muhammad \& Dwi, Analisis Perilaku...

\begin{tabular}{|c|c|c|}
\hline \multicolumn{2}{|r|}{ Item } & r hitung \\
\hline X3.1 & $\begin{array}{l}\text { Usia mempengaruhi pola pikir saya } \\
\text { untuk berwisata ke Pantai Dendang } \\
\text { Melayu }\end{array}$ & 0,628 \\
\hline X3.2 & $\begin{array}{l}\text { Pekerjaan saya dapat mempengaruhi } \\
\text { saya dalam berwisata ke Pantai } \\
\text { Dendang Melayu }\end{array}$ & 0,731 \\
\hline X3.3 & $\begin{array}{l}\text { Kondisi ekonomi dapat } \\
\text { mempengaruhi saya untuk berwisata } \\
\text { ke Pantai Dendang Melayu }\end{array}$ & 0,532 \\
\hline X 3.4 & \begin{tabular}{lrrr} 
Tingkat & \multicolumn{2}{r}{ penghasilan } & saya \\
memungkinkan & saya & untuk \\
berwisata ke & Pantai & Dendang
\end{tabular} & 0,686 \\
\hline X3.5 & $\begin{array}{l}\text { Melakukan perjalanan wisata } \\
\text { merupakan hobi saya }\end{array}$ & 0,486 \\
\hline X3.6 & $\begin{array}{l}\text { Saya berwisata ke Pantai Dendang } \\
\text { Melayu karena merupakan tempat } \\
\text { favorit saya }\end{array}$ & 0,330 \\
\hline X3.7 & $\begin{array}{l}\text { Saya berwisata ke Pantai Dendang } \\
\text { Melayu karena mengikuti tren }\end{array}$ & 0,575 \\
\hline X3.8 & $\begin{array}{l}\text { Saya sudah sering mengunjungi } \\
\text { Pantai Dendang Melayu }\end{array}$ & 0,737 \\
\hline X4.1 & $\begin{array}{l}\text { Dengan berkunjung ke Pantai } \\
\text { Dendang Melayu membuat pikiran } \\
\text { saya terasa segar dan merasa tenang }\end{array}$ & 0,635 \\
\hline $\mathrm{X} 4.2$ & $\begin{array}{l}\text { Dorongan dari dalam diri saya, } \\
\text { untuk mengunjungi Pantai Dendang } \\
\text { Melayu akan menimbulkan se- } \\
\text { mangat di kemudian hari untuk } \\
\text { mengunjunginya lagi }\end{array}$ & 0,666 \\
\hline $\mathrm{X} 4.3$ & $\begin{array}{l}\text { Saya merasa Pantai Dendang } \\
\text { Melayu cocok utuk saya kunjungi }\end{array}$ & 0,537 \\
\hline X4.4 & $\begin{array}{l}\text { Ketersediaan fasilitas di Pantai } \\
\text { Dendang Melayu tidak membuat } \\
\text { saya mengunjungi tempat wisata } \\
\text { lain }\end{array}$ & 0,539 \\
\hline$X 4.5$ & $\begin{array}{l}\text { Pengalaman saya di Pantai Dendang } \\
\text { Melayu membuat saya ingin } \\
\text { mendatangi lagi di lain waktu }\end{array}$ & 0,767 \\
\hline Y1 & $\begin{array}{l}\text { Saya mengunjungi Pantai Dendang } \\
\text { Melayu karena saya tahu pantai ini } \\
\text { cocok untuk dikunjungi }\end{array}$ & 0,531 \\
\hline Y2 & $\begin{array}{l}\text { Pemandangan dan panorama yang } \\
\text { ada di Pantai Dendang Melayu } \\
\text { membuat saya terkesan }\end{array}$ & 0,718 \\
\hline Y3 & $\begin{array}{l}\text { Pantai Dendang Melayu } \\
\text { menawarkan tempat wisata yang } \\
\text { sangat beragam (wisata makanan, } \\
\text { minuman, dan hiburan) }\end{array}$ & 0,681 \\
\hline Y4 & $\begin{array}{l}\text { Kebersihan dan keamanan Pantai } \\
\text { Dendang Melayu sudah baik }\end{array}$ & 0,449 \\
\hline Y5 & $\begin{array}{l}\text { Fasilitas sarana prasarana yang ada } \\
\text { di Pantai Dendang Melayu sudah } \\
\text { lengkap dan memadai }\end{array}$ & 0,432 \\
\hline Y6 & $\begin{array}{l}\text { Saya memilih berwisata ke Pantai } \\
\text { Dendang Melayu karena sudah } \\
\text { menawarkan tempat wisata yang pas } \\
\text { menurut saya }\end{array}$ & 0,690 \\
\hline Y7 & $\begin{array}{l}\text { Saya berwisata ke Pantai Dendang } \\
\text { Melayu hanya pada hari libur atau } \\
\text { hari besar lainnya }\end{array}$ & 0,616 \\
\hline
\end{tabular}

Tabel 3. Hasil Uji Reliabilitas

\begin{tabular}{|l|c|}
\hline \multicolumn{1}{|c|}{ Variabel } & Alpha Cronbach \\
\hline Faktor Budaya (X1) & 0,728 \\
\hline Faktor Sosial (X2) & 0,606 \\
\hline Faktor Pribadi (X3) & 0,710 \\
\hline Faktor Psikologi (X4) & 0,604 \\
\hline Keputusan Berkunjung (Y) & 0,662 \\
\hline \multicolumn{2}{|c|}{ Sumber : Data primer yang diolah, 2018 }
\end{tabular}

\section{Uji Asumsi Klasik}

\section{Uji Normalitas}

Pengujian normalitas ini dilakukan dengan menggunakan uji Kolmogorov Smirnov. Karena nilai signifikan $>0,1$ maka dapat disimpulkan bahwa distribusi residual data penelitian adalah normal.

\section{Uji Multikolinearitas}

Uji multikolinearitas bertujuan untuk menguji apakah model regresi ditemukan adanya korelasi antar variabel bebas (independen). Untuk dapat menentukan apakah terdapat multikolinearitas dalam model regresi pada penelitian ini adalah dengan melihat nilai VIF (Variance Inflation Factor). Adapun nilai VIF dapat dilihat pada tabel diawah ini

Tabel 4. Hasil Uji Multikolinearitas

\begin{tabular}{|l|r|c|}
\hline Variabel & Tolerance & VIF \\
\hline Faktor Budaya & 0,562 & 1,780 \\
\hline Faktor Sosial & 0,901 & 1,110 \\
\hline Faktor Pribadi & 0,580 & 1,723 \\
\hline Faktor Psikologi & 0,522 & 1,917 \\
\hline
\end{tabular}

Karena nilai VIF kurang dari 10 dan atau nilai Tolerance lebih dari 0,01 maka dapat disimpulkan dengan tegas bahwa tidak terdapat masalah multikolinearitas.

\section{Uji Heteroskedastisitas}

Uji heteroskedastisitas bertujuan untuk mengetahui kesalahan pendugaan dalam model regresi dari seluruh sampel pengamatan dimana semua kesalahan pendugaan model regresi dari semua sampel pengamatan memiliki varian yang sama (homokedastis). Dalam penelitian ini metode yang digunakan untuk mendeteksi terjadinya heteroskedastisitas adalah dengan uji Spearman's Rho. 
Tabel 5. Hasil Uji Heterokedastisitas

\begin{tabular}{|l|r|}
\hline Variabel & Signifikansi (Sig. 2-tailed) \\
\hline Faktor Budaya & 0,911 \\
\hline Faktor Sosial & 0,586 \\
\hline Faktor Pribadi & 0,495 \\
\hline Faktor Psikologi & 0,857 \\
\hline
\end{tabular}

\section{HASIL DAN PEMBAHASAN}

Analisis regresi linear berganda digunakan dalam penelitian ini dengan tujuan untuk mengetahui ada tidaknya pengaruh variabel bebas terhadap variabel terikat. Ringkasan hasil pengolahan data dengan menggunakan program SPSS tersebut adalah sebagai berikut :

Tabel 6. Hasil Regresi Linear

\begin{tabular}{|l|c|c|}
\hline Variabel & Unstandardized Coefficient & Sig. \\
\hline Faktor Budaya & 0,637 & 0,000 \\
\hline Faktor Sosial & 0,235 & 0,014 \\
\hline Faktor Pribadi & 0,422 & 0,000 \\
\hline Faktor Psikologi & 1,102 & 0,000 \\
\hline
\end{tabular}

Beberapa hal yang dapat diketahui dari persamaan tersebut sebagai berikut:

1. Variabel Faktor Budaya memiliki koefisien sebesar 0,637 dan bernilai positif, berarti jika variabel Faktor Budaya mengalami kenaikan satu satuan, maka Keputusan Berkunjung akan mengalami peningkatan sebesar 0,637 satuan dengan asumsi variabel independen lainnya bernilai tetap.

2. Variabel Faktor Sosial memiliki keofisien sebesar 0,235 dan bernilai positif, berarti jika variabel Faktor Sosial mengalami peningkatan sebesar satu satuan, maka Keputusan Berkunjung akan mengalami peningkatan sebesar 0,235 satuan dengan asumsi variabel independen lainnya benilai tetap.

3. Variabel Faktor Pribadi memiliki koefisien sebesar 0,422 dan bernilai positif, berarti jika variabel Faktor Pribadi mengalami kenaikan sebesar satu satuan, maka Keputusan Berkunjung akan mengalami peningkatan sebesar 0,422 satuan dengan asumsi variabel independen lainnya bernilai tetap.

4. Variabel Faktor Psikologi memiliki keofisien sebesar 1,102 dan bernilai positif, berarti jika variabel Faktor Psikologi mengalami kenaikan sebesar satu satuan, maka Keputusan Berkunjung akan mengalami peningkatan sebesar 1,102 satuan dengan asumsi variabel independen lainnya bernilai tetap.

\section{Uji Hipotesis}

Berdasarkan tabel 6, karena taraf signifikansi pada tabel semua dibawah $\alpha=$ $10 \%$, maka dapat disimpulkan bahwa keempat faktor perilaku konsumen secara parsial berpengaruh terhadap Pemilihan Tempat Wisata. Nilai thitung positif artinya pengaruh yang terjadi adalah positif, atau dapat diartikan semakin tinggi atau baik suatu faktor, maka semakin meningkatkan Pemilihan Tempat Wisata. Hasil penelitian ini mendukung hasil penelitian sebelumnya yang dilakukan oleh Yuriska dan Sukirno (2014) yang menyatakan bahwa keempat faktor yaitu budaya, sosial, pribadi, dan psikologi berpengaruh positif dan signifikan terhadap keputusan konsumen.

\section{KESIMPULAN Simpulan}

Berdasarkan pembahasan hasil penelitian diatas dapat ditarik kesimpulan bahwa keempat faktor, yaitu Faktor Budaya (X1), Faktor Sosial (X2), Faktor Pribadi (X3), dan Faktor Psikologi (X4) memiliki pengaruh yang positif dan signifikan terhadap pemilihan tempat wisata Pantai Dendang Melayu.

\section{Saran}

Berdasarkan kesimpulan dalam penelitian ini, maka saran yang dapat dijadikan pertimbangan adalah:

1. Untuk pemerintah daerah untuk memperhatikan bahwa perilaku pengunjung pantai Dendang Melayu adalah rasional, sehingga sejumlah strategi promosi untuk mempengaruhi kunjungan wisatawan tetap relevan.

2. Untuk penelitian selanjutnya untuk menambahkan variabel lain yang mempengaruhi Pemilihan Tempat Wisata utamanya variabel di luar faktor konsumen atau faktor eksternal seperti promosi, harga, dan sebagainya. 


\section{DAFTAR PUSTAKA}

Ghozali, Imam. (2016). Aplikasi Analisis Multivariate Dengan Program IBM SPSS 23. Semarang: Badan Penerbit Universitas Diponegoro.

Kaur, N., Singh, D.P. (2017) Deciphering the consumer behaviour facets of functional foods: A literature review. Appetite, 90, 1-40. doi: 10.1016

Koesoemaningsih, R. (2013). Pengaruh Budaya, Sosial, Pribadi Dan Psikologi Terhadap Keputusan Mahasiswa Dalam Memilih Pendidikan Pada Prodi Manajemen Fakultas Ekonomi Universitas Soerjo Ngawi. Media Soerjo, 13 (2), 1-21. ISSN: 1978-6239

Kotler, P., \& Keller, K.L. (2008). Manajemen Pemasaran (Edisi 13). Jakarta: Erlangga.

Malau, H.,Ph.D. (2017) Manajemen Pemasaran Teori dan Aplikasi Pemasaran Era Tradisional Sampai Era Modernisasi Global. Bandung: Alfabeta.

Salamah, N.N.A. (2015) Pengaruh Perilaku Konsumen Terhadap Keputusan Pembelian Kosmetika Sari Ayu Pada Toko La Tahzan Palembang. Jurnal Wahana Media Ekonomika, 2 (1), 113. ISSN: 1693-4091

Sugiyono. (2007). Statistika Untuk Penelitian, Cetakan kedua belas. Bandung: Alfabeta

Supranto, J., \& Limakrisna, N. (2011). Perilaku Konsumen \& Strategi Pemasaran Untuk Memenangkan Persaingan Bisnis, edisi kedua. Jakarta: Mitra Wacana Media.

Supriyono, \& Iskandar. D. (2015). Pengaruh Faktor Budaya, Sosial, Individu Dan Psikologis Terhadap Keputusan Konsumen Membeli Di Indomaret. Kelola, 2 (3), 43-60. ISSN: 2337-5965

Yuriska, M.R., \& Sukirno, I. (2014) Pengaruh Faktor Sosial, Personal, Psychological dan Kultural Terhadap Keputusan Pembelian Konsumen Centro Department Store Melalui
Stimulus Midnight Sale. Modus, 26

(1), 77-84. ISSN: 0852-1875 